\title{
Adiponectin-induced secretion of interleukin-6 (IL-6), monocyte chemotactic protein- I (MCP-I, CCL2) and interleukin-8 (IL-8, CXCL8) is impaired in monocytes from patients with type I diabetes

\author{
Sabine Abke ${ }^{1}$, Markus Neumeier ${ }^{1}$, Johanna Weigert ${ }^{1}$, Gabriele Wehrwein ${ }^{1}$, \\ Elke Eggenhofer ${ }^{1}$, Andreas Schäffler ${ }^{1}$, Kevin Maier ${ }^{1}$, Charalampos Aslanidis ${ }^{2}$, \\ Jürgen Schölmerich ${ }^{1}$ and Christa Buechler*1
}

Address: ${ }^{1}$ Department of Internal Medicine I, University of Regensburg, D-93042 Regensburg, Germany and ${ }^{2}$ Institute of Clinical Chemistry and Laboratory Medicine, University of Regensburg, D-93042 Regensburg, Germany

Email: Sabine Abke - abs507310@gw.ngate.uni-regensburg.de; Markus Neumeier - markus.neumeier@klinik.uni-regensburg.de; Johanna Weigert - johanna.weigert@klinik.uni-regensburg.de; Gabriele Wehrwein - gwehrwein@yahoo.de;

Elke Eggenhofer - elke.eggenhofer@klinik.uni-regensburg.de; Andreas Schäffler - andreas.schaeffler@klinik.uni-regensburg.de;

Kevin Maier - kevinmaier@arcor.de; Charalampos Aslanidis - charalampos.aslanidis@klinik.uni-regensburg.de;

Jürgen Schölmerich - juergen.schoelmerich@klinik.uni-regensburg.de; Christa Buechler* - christa.buechler@klinik.uni-regensburg.de

* Corresponding author

\section{Published: 30 August 2006}

Cardiovascular Diabetology 2006, 5:17 doi:10.1186/1475-2840-5-17

This article is available from: http://www.cardiab.com/content/5/I/I7

(C) 2006 Abke et al; licensee BioMed Central Ltd.

This is an Open Access article distributed under the terms of the Creative Commons Attribution License (http://creativecommons.org/licenses/by/2.0), which permits unrestricted use, distribution, and reproduction in any medium, provided the original work is properly cited.
Received: 02 August 2006

Accepted: 30 August 2006

\begin{abstract}
Background: Systemic adiponectin is reduced in patients with cardiovascular disease (CVD) and low adiponectin may contribute to the pathogenesis of atherosclerosis. However, circulating adiponectin is elevated in type I diabetes (TID) patients, who have also a higher incidence to develop CVD. Because monocytes play an important role in atherosclerosis, we analysed the influence of adiponectin on cytokine and chemokine release in monocytes from TID patients and controls.
\end{abstract}

Methods: Systemic adiponectin was determined in the plasma and the high-molecular weight (HMW) form of adiponectin was analysed by immunoblot. Monocytes were isolated from TID patients and controls and the adiponectin-stimulated release of interleukin-6 (IL-6), monocyte chemotactic protein-I (MCP-I, CCL2) and interleukin-8 (IL-8, CXCL8) was analysed.

Results: Systemic adiponectin was higher in TID patients. Immunoblot analysis of the plasma indicate abundance of HMW adiponectin in TID patients and controls. IL-6, CCL2 and CXCL8 secretion in response to adiponectin were found induced in monocytes from controls whereas only IL- 6 was upregulated in TID cells. The induction of IL- 6 by adiponectin was abrogated by an inhibitor of the NFKB pathway.

Conclusion: These data indicate that adiponectin-mediated induction of IL-6, CCL2 and CXCL8 is disturbed in monocytes from TID patients and therefore elevated systemic adiponectin in TID patients may be less protective when compared to controls. 


\section{Background}

The adipokine adiponectin (APM) is known to exert antiinflammatory and insulin-sensitizing effects [1] but recent studies also describe proinflammatory activities of APM $[2,3]$. APM is highly abundant in human plasma and is secreted by adipose tissue in inverse relation to the body mass index [1]. APM circulates in blood as trimers, hexamers, and higher molecular weight (HMW) complexes [4]. A proteolytic cleavage product of adiponectin that includes its globular head group has also been detected in human plasma [5]. The biological activity of APM depends on its high order structure with different oligomeric complexes activating different signaling pathways. HMW-APM activates the NFKB pathway and consequently induces the secretion of IL- 6 in differentiated THP- 1 cells and primary monocytes $[2,4]$. Besides NFkB, HMW-APM also activates AMP-activated protein kinase (AMPK) [2] and stimulation of AMPK by metformin, a drug used in patients with impaired glucose tolerance, also induces IL6 in cardiac fibroblasts [6]. Release of the chemokines CCL2 and CXCL8 is also stimulated by HMW-APM in human monocytes and may depend on NFkB activation $[3,7]$.

Chemokines are molecules that attract cells of the immune system to the site of inflammation and also mediate the migration of monocytes to the subendothelium, an early event in the formation of atherosclerotic lesions. Like CCL2, CXCL8 is produced by a variety of cell types and is induced by proinflammatory mediators like endotoxin [8]. Both chemokines attract cells of the immune system to sites of inflammation and CXCL8 is unique among these proteins because of its high stability in-vivo [9]. The best characterized CC chemokine is CCL2 (MCP-1) and several studies suggest that CCL2 is the main chemokine involved in the recruitment of monocytes from blood into early atherosclerotic lesions. CXCL8 stimulates the adhesion of monocytes to endothelial cells and has also been linked to the development of atherosclerosis [10].

Whereas circulating adiponectin is reduced in the sera of patients with type 2 diabetes (T2D) and in patients with cardiovascular disease (CVD) [1], systemic adiponectin is elevated in type 1 diabetes mellitus (T1D), that is also associated with macro- and microvasculature complications $[11,12]$. Several studies demonstrate a disturbed response of T1D monocytes to endotoxin shown by an altered cytokine and chemokine secretion $[13,14]$. Because HMW-APM and endotoxin activate NFkB it might be suggested that T1D monocytes show an altered response to HMW-APM.

Monocytes are involved in the innate immune response and the formation of early atherosclerotic lesions. An altered cytokine and chemokine release from these cells may contribute to premature atherosclerosis and reduced immune function in T1D patients $[15,16]$. Therefore the influence of HMW-APM on the secretion of the multifunctional cytokine IL-6 and the chemokines CCL2 and CXCL8 was determined in monocytes of T1D patients and controls.

\section{Methods \\ Patients and controls}

Monocytes were purified from the blood of 10 female controls and 10 female T1D patients. The median age of the controls was 24 years (range $24-43$ ) and of the patients 36.5 years (range $18-46$ ). The mean body mass index (BMI) of controls was $20.6 \mathrm{~kg} / \mathrm{m}^{2}$ (range 17.5 22.3 ) and of the T1D patients $22.3 \mathrm{~kg} / \mathrm{m}^{2}$ (range 19.5 31 ). Only patients with a known history of T1D and an established therapy with intensive insulin treatment were recruited for the study. The median duration of diabetes was 13.5 years (range $7-34$ ). The mean HbA1c was 7.2 $\%$ (range 5.7 - 9.5). Patients had no infectious disease within two weeks before blood was drawn. C-reactive protein was determined by an ELISA from Anogen (Ontario, Canada) in the plasma and was $1.94 \mathrm{mg} / \mathrm{l}$ (range $0.5-5$ ) in controls and $1.1 \mathrm{mg} / \mathrm{l}$ (range $0.7-1.6$ ) in T1D. All women gave informed consent and the study was approved by the local Medical Ethical Committee.

\section{Reagents}

Macrophage SFM medium was from Gibco BRL (Karlsruhe, Germany). Recombinant M-CSF, recombinant human adiponectin, polyclonal adiponectin antibody and CXCL8 ELISA were from R\&D Systems (WiesbadenNordenstadt, Germany), IL-6 ELISA was from Pierce Biotechnology (Rockford, Illinois), and CCL2 ELISA was obtained from Amersham Biosciences (Freiburg, Germany). E. coli derived recombinant human proteins were used as standard for the IL-6, CXCL8 and CCL2 ELISAs. Apo E antibody was from Chemicon (Hampshire, U.K.). Vacutainer CPT were from Becton Dickinson (Franklin Lakes, NJ). InSolution ${ }^{\mathrm{TM}}$ NF- $\kappa \mathrm{B}$ Activation Inhibitor was from Calbiochem (Darmstadt, Germany).

\section{Isolation and culture of primary blood monocytes}

Peripheral blood leukocytes were isolated from $16 \mathrm{ml}$ of whole blood by Vacutainer CPT and monocytes were further purified by magnetic separation with CD14 beads (Miltenyi Biotec, Bergisch Gladbach, Germany). Purity of the isolated monocytes was determined by flow cytometric analysis and was more than 98\%. 500,000 monocytes were cultivated in $500 \mu \mathrm{l}$ macrophage SFM medium in 24 well plates with $50 \mathrm{ng} / \mathrm{ml} \mathrm{M-CSF}$ for $24 \mathrm{~h}$. Subsequently the medium was replaced. Monocytes were either cultivated in $500 \mu \mathrm{l}$ macrophage SFM medium with M-CSF or in the identical media supplemented with $10 \mu \mathrm{g} / \mathrm{ml}$ 
HMW-APM. Supernatants were collected 24 h later and used for ELISA.

\section{SDS-PAGE and immunoblotting}

The plasma was diluted 1,000-fold in PBS and $10 \mu$ l were separated by SDS-polyacrylamide gel electrophoresis and were transferred to PVDF membranes (Bio-Rad, Germany). To analyse ApoE either $10 \mu \mathrm{g}$ cellular lysate or 10 $\mu \mathrm{l}$ of the supernatants were used. Incubations with antibodies were performed in 1\% BSA in PBS, $0.1 \%$ Tween overnight. Detection of the immune complexes was carried out with the ECL Western blot detection system (Amersham Pharmacia, Deisenhofen, Germany).

\section{Statistics}

Data are represented as Box Plots indicating the median, the upper and lower quartile, the largest and the lowest value in the data set. Data are given as median values and the range of the values. Statistical differences were analyzed by two tailed Mann-Whitney $U$ Test and a value of $P$ $<0.05$ was considered as statistically significant.

\section{Results}

Systemic adiponectin in the plasma of controls and TID patients

Adiponectin was determined in the plasma of controls and was found to be higher in the patients. While the controls had $9.8 \mu \mathrm{g} / \mathrm{ml}$ (range 5.6-21.5), the T1D patients had $18.4 \mu \mathrm{g} / \mathrm{ml}$ (range 7.2-25.4) in their plasma (Figure $1 \mathrm{~A})$. The difference is significant with $\mathrm{p}=0.04$. Immunoblots were performed with plasma samples from controls and T1D patients which was seperated by SDS-PAGE under non-reducing conditions and HMW-APM was detected in all plasma samples (Figure 1B). Reducing conditions convert the HMW-APM to two protein subunits most likely resembling dimeric and trimeric APM (Figure 1C) and both multimers were detected in the plasma of the controls and T1D patients indicating a similar abundance of HMW adiponectin (Figure 1D).

\section{HMW-APM-induced IL-6 secretion in monocytes from controls and TID patients}

IL-6 was determined in the supernatants of monocytes incubated with or without HMW-APM by ELISA. IL-6 was elevated in the supernatants of HMW-APM incubated cells. The median of HMW-APM induced secretion in monocytes from controls was $64.4 \mathrm{pg} / \mathrm{ml}$ (range 11.6119.3) and in monocytes isolated from T1D patients 31.9 $\mathrm{pg} / \mathrm{ml}$ (range 0-81.7) (Figure 2A). Therefore a significant lower IL-6 release in monocytes from T1D patients $(\mathrm{p}=$ 0.01 ) was observed upon HMW-APM treatment.

\section{HMW-APM-induced CCL2 secretion in monocytes from controls and TID patients}

The supernatants described above were also used to measure CCL2. CCL2 is constitutively secreted by non-stimulated monocytes and its concentration was $1,416 \mathrm{pg} / \mathrm{ml}$ (range 418-6,019) in controls and 1,198 pg/ml (range 208-3,227) in monocytes from T1D patients (Figure 2B) thus being similar in unstimulated monocytes isolated from controls or T1D patients. In HMW-APM-treated cells CCL2 secreted from control monocytes was $1,919 \mathrm{pg} / \mathrm{ml}$ (range 704-7,387) ( $\mathrm{p}=0.007$ vs unstimulated cells) and from T1D $992 \mathrm{pg} / \mathrm{ml}$ (range 191-4,643) ( $\mathrm{p}=0.08$ vs unstimulated cells) (Figure 2B).

\section{HMW-APM induced CXCL8 secretion in monocytes from controls and TID patients}

Furthermore CXCL8 was determined in the supernatants by ELISA. CXCL8 is already expressed in non-stimulated monocytes and its concentration was $276,000 \mathrm{pg} / \mathrm{ml}$ (range 78,500-382,000) in controls and 312,250 $(82,500-358,000)$ in monocytes from T1D patients indicating a similar release of this chemokine $(\mathrm{p}=0.47)$ (Figure 2C). CXCL8 in HMW-APM-activated monocytes from controls was 335,000 pg/ml (range 91,000 - 610,000) (p vs control $=0.02$ ) and $213,500 \mathrm{pg} / \mathrm{ml}$ (range $77,000-$ $334,500)$ in T1D monocytes $(\mathrm{p}=0.13)$ (Figure 2C) and therefore was not induced by HMW-APM in monocytes from T1D patients.

\section{Metformin does not induce IL-6 in primary human monocytes}

Monocytes from three different donors were incubated with $0.5 \mathrm{mM}$ metformin for $24 \mathrm{~h}$ and IL- 6 was determined in their supernatants. Our results demonstrate a similar release of IL- 6 in unstimulated and metformin-treated monocytes (Figure 3A).

\section{Inhibition of NFKB abrogates HMW-APM stimulated IL6 release}

Monocytes from 2 different donors were incubated with $10 \mu \mathrm{g} / \mathrm{ml}$ HMW-APM alone or in combination with 2.5, 5.0 or $10.0 \mu \mathrm{M}$ InSolution ${ }^{\mathrm{TM}} \mathrm{NF}-\kappa \mathrm{B}$ Activation Inhibitor for 24 h. IL-6 secretion in control treated cells was set to $100 \%$ and HMW-APM induced IL-6 release was $170 \%$ (range 149-225). Whereas $2.5 \mu \mathrm{M}$ inhibitor did not significantly reduce IL- 6 (166\%, range $81-224), 5 \mu \mathrm{M}$ reduce HMW-APM mediated IL- 6 release to $144 \%$ (range $60-$ $173, \mathrm{p}=0.02$ ) and $10 \mu \mathrm{M}$ reduce APM mediated IL-6 secretion to $116 \%$ (range $60-144, \mathrm{p}=0.0004$ ) as is shown in Figure 3B.

\section{Apolipoprotein $E$ is not altered by HMW-APM}

Apolipoprotein E (Apo E) secretion in monocytes is suppressed by endotoxin and therefore the influence of HMW-APM on intracellular Apo E was also studied. Nei- 

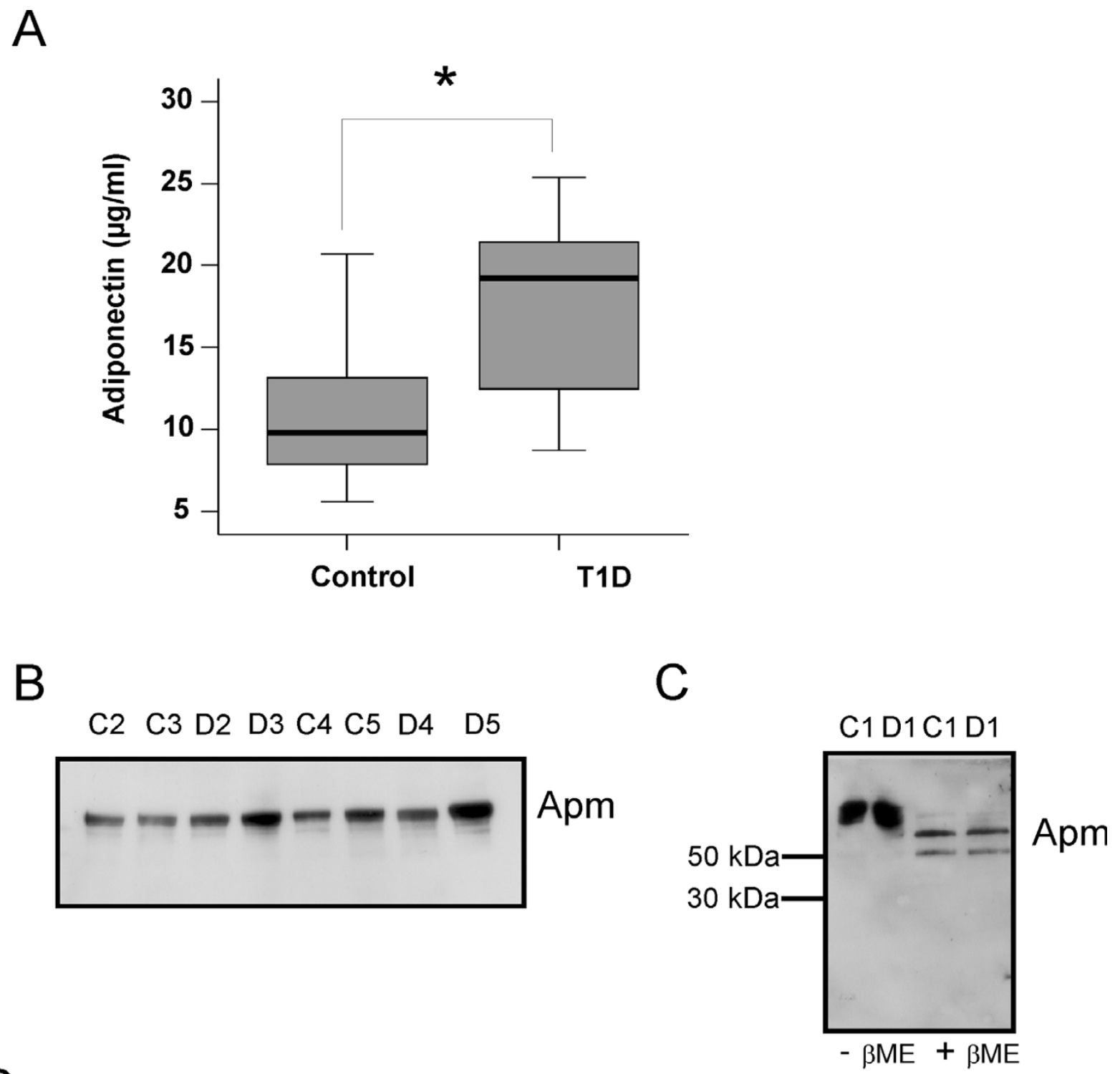

$\mathrm{D}$

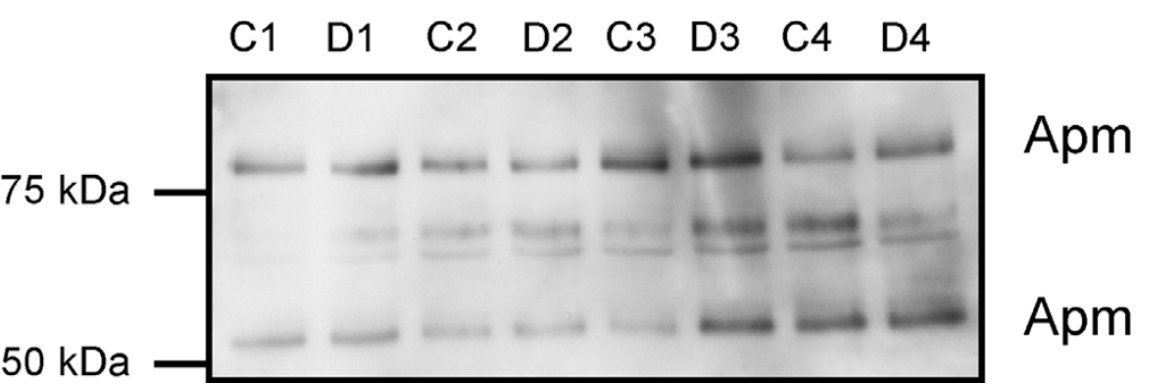

Figure I

Systemic adiponectin in TID patients and controls. (A) Systemic adiponectin was determined by ELISA in the plasma of I 0 controls and IO TID patients. (B) Immunoblot of plasma adiponectin separated by SDS-PAGE under non-reducing conditions with plasma from controls (C2 to C5) and TID patients (D2 to D5). (C) Immunoblot of plasma adiponectin separated by SDS-PAGE under non-denaturing (- $\beta M E)$ or denaturing conditions $(+\beta M E)$ from control I (CI) and TID patient I (DI). (D) Immunoblot of plasma adiponectin separated by SDS-PAGE under reducing conditions with plasma from controls (CI to $\mathrm{C} 4)$ and TID patients (DI to D4). 
A

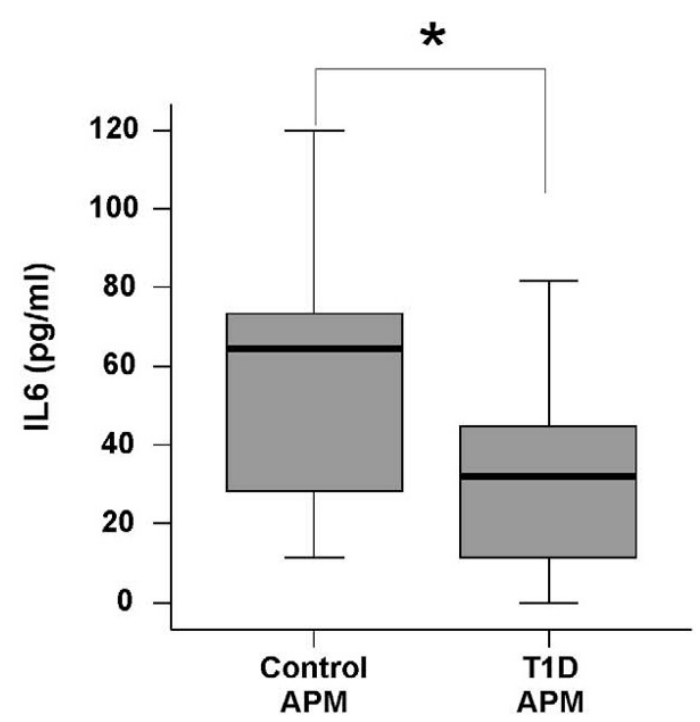

C

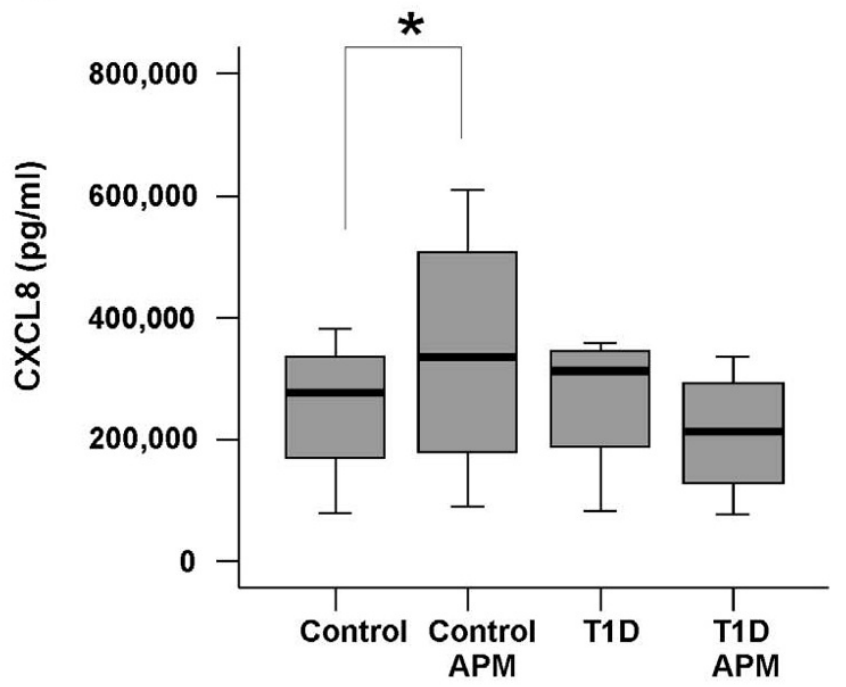

B

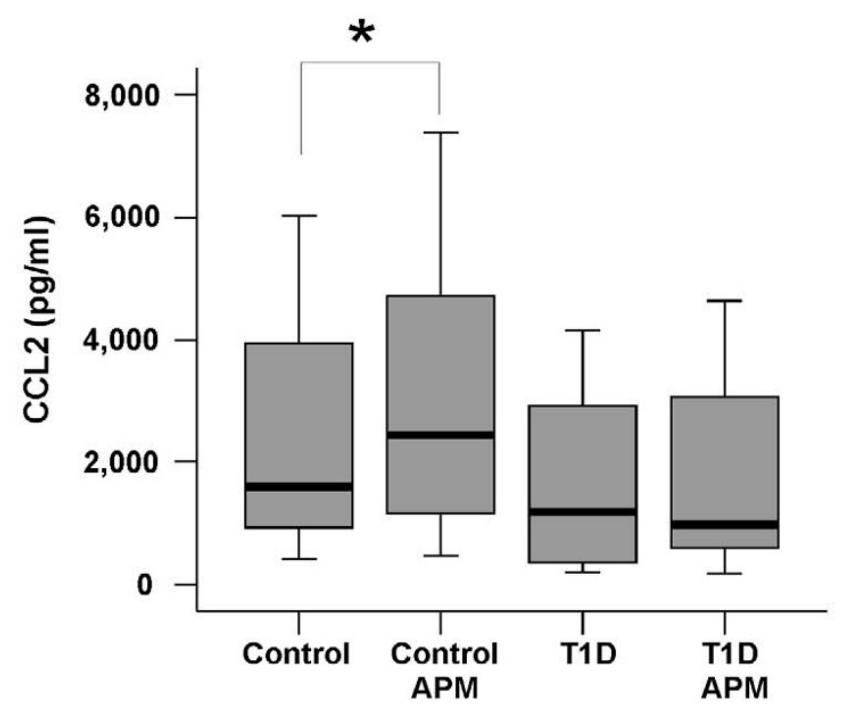

\section{Figure 2}

HMW-APM stimulated IL-6, CCL2 and CXCL8 secretion of TID and control monocytes. Monocytes from I0 controls and IO TID patients were cultivated as described in the text. IL-6 (A), CCL2 (B) and CXCL8 (C) were determined in the supernatant of cells treated with $10 \mu \mathrm{g} / \mathrm{ml} \mathrm{HMW-APM}$ for $24 \mathrm{~h}$. CCL2 (B) and CXCL8 (C) were also determined in unstimulated monocytes.

ther intracellular nor secreted Apo E is altered by HMWAPM when monocytes from 3 different donors were analysed and the results from monocytes of 2 donors is shown (Figure 4) indicating that not all genes that respond to endotoxin are altered by HMW-APM.

\section{Discussion}

Systemic adiponectin was found elevated in T1D patients $[11,12]$ and this is also the case in the study group investigated in this work. HMW-APM is currently suggested to represent the biologic active form of adiponectin [17] and 

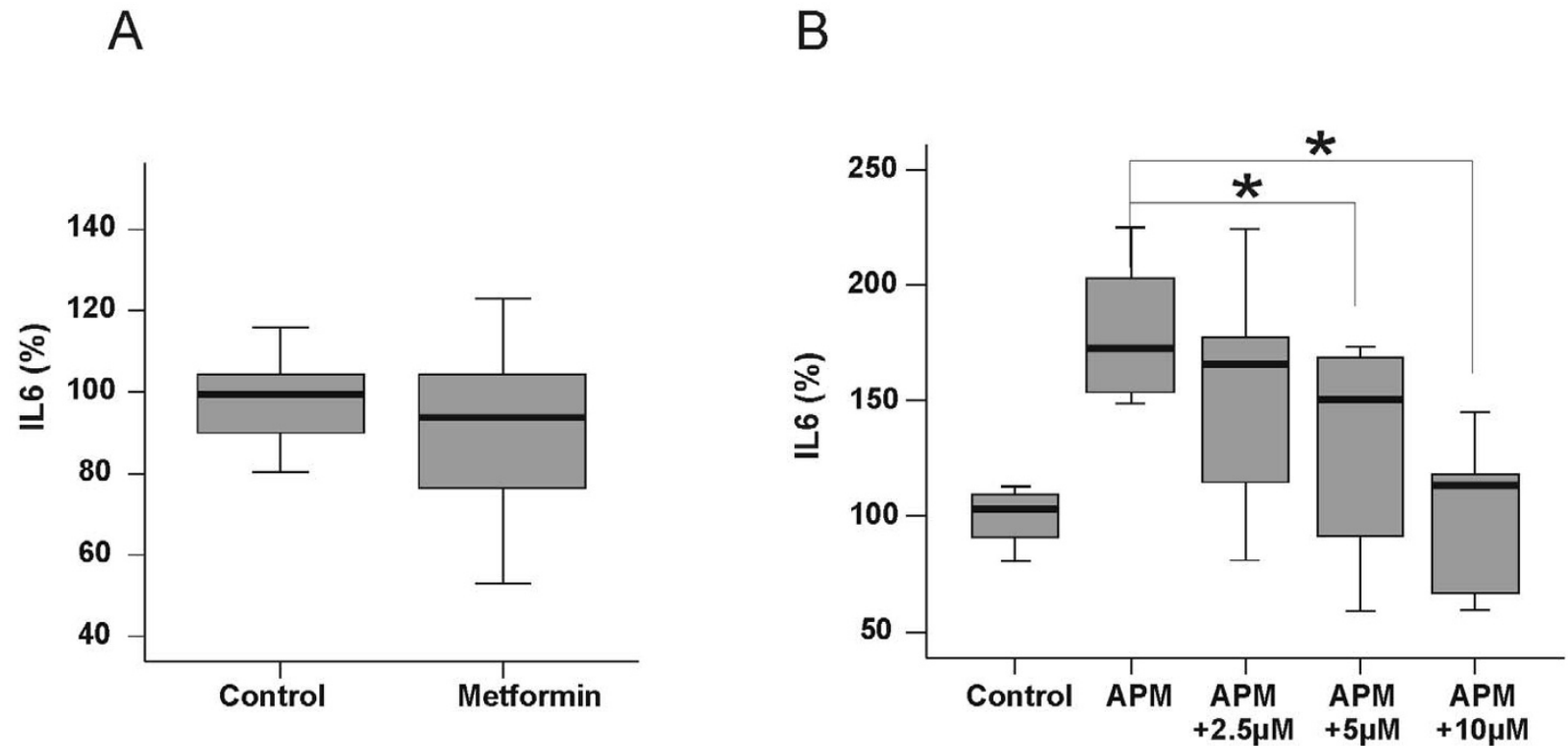

\section{Figure 3}

Influence of metformin on IL-6 release and inhibiton of HMW-APM stimulated IL-6 by a NF $\kappa$ B inhibitor. (A) Monocytes from 3 controls were cultivated with $0.5 \mathrm{mM}$ metformin for $24 \mathrm{~h}$ and IL-6 was determined. (B) Monocytes from 2 different donors were incubated with $10 \mu \mathrm{g} / \mathrm{ml} \mathrm{HMW}-\mathrm{APM}$ alone or in combination with $2.5,5.0$ or $10.0 \mu \mathrm{M}$ InSolution ${ }^{\mathrm{TM}} \mathrm{NF}$ $\kappa \mathrm{B}$ Activation Inhibitor for $24 \mathrm{~h}$ and IL- 6 was measured.

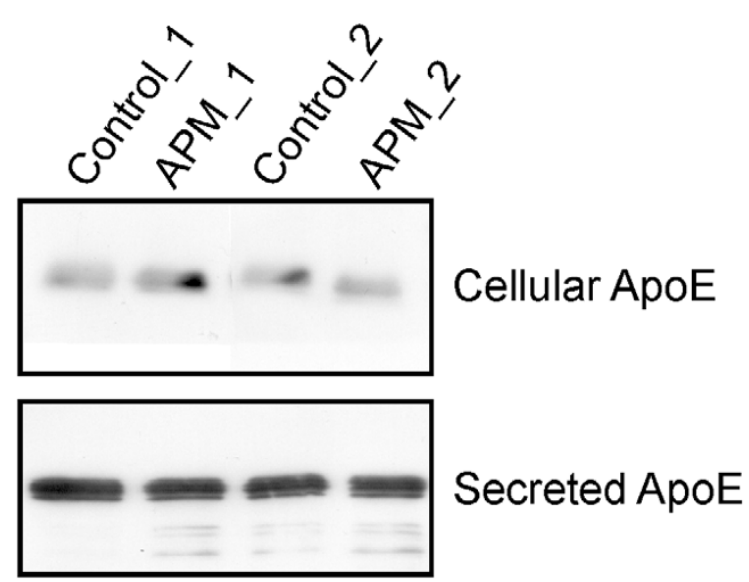

Figure 4

HMW-APM does not regulate Apo E. Cellular and secreted Apo $E$ was analyzed by immunoblot in monocytes treated with PBS as solvent control or HMW-APM and the results for monocytes of 2 different donors is shown. was detected in control and T1D plasma when analysed by immunoblot.

Several studies describe antiinflammatory effects of adiponectin in activated monocytes and E. coli produced fulllength adiponectin at a concentration of $10 \mu \mathrm{g} / \mathrm{ml}$ was effective in reducing tumor necrosis factor $\alpha$ and IL-6 $[18,19]$. Full-length human adiponectin produced in a mouse cell line $(10 \mu \mathrm{g} / \mathrm{ml})$, however, induces IL-6, CXCL8 and CCL2 [2,7] in primary human monocytes whereas full-length human adiponectin produced in insect cells (1 $\mu \mathrm{g} / \mathrm{ml}$ ) has antiinflammatory properties [2]. In microvascular endothelial cells, full-length human adiponectin produced in the mouse cell line also upregulates CCL2 and CXCL8 whereas mesangial cells did not respond even when $50 \mu \mathrm{g} / \mathrm{ml}$ of adiponectin were used [7]. The recombinant globular adiponectin from mammalian cells (10 and $25 \mu \mathrm{g} / \mathrm{ml}$ were tested) did not upregulate CXCL8 and CCL2 in microvascular endothelial cells and furthermore could not block full-length adiponectin induced chemokine secretion [7]. A further study describes an induction of tumor necrosis factor $\alpha$ and IL- 6 in macrophages by globular adiponectin $(10 \mu \mathrm{g} / \mathrm{ml})$ [20]. Adiponectin purified from human plasma stimulated CXCL8 in activated 
monocytes and inhibited CXCL8 in the presence of apoptotic cells [3].

The data from the literature indicate that the effects of adiponectin may depend on its high order structure, posttranslational modification and on the activation state of the monocytes investigated. However, comparative studies have to be performed to identify the reasons for these different findings.

In the present study full-length human adiponectin produced in a mouse cell line was used and IL-6, CCL2 and CXCL8 were found induced in monocytes isolated from healthy controls.

When compared to monocytes isolated from controls, T1D cells show a reduced response to HMW-APM. Whereas HMW-APM stimulated secretion of IL-6 was lower in T1D monocytes, HMW-APM did not induce CCL2 or CXCL8 in T1D cells. Release of IL-6 and CCL2 is also lower in T1D cells when treated with endotoxin [14]. HMW-APM and endotoxin mediated increase of IL6 depends on the activation of $\mathrm{NFKB}$ indicating that $\mathrm{NF \kappa B}$ signaling is partly impaired in T1D monocytes. In contrast, CXCL8 is similarily induced in T1D monocytes and control cells by endotoxin but not stimulated by HMWAPM in the patients' cells although upregulation of this chemokine, at least by endotoxin, also depends on NFKB [8]. Apo E is reduced by endotoxin [14] whereas HMWAPM did not alter Apo E in human monocytes. Therefore not all proteins are similarily regulated by endotoxin and HMW-APM.

IL-6 is higher in the sera of patients with T1D, T2D and in patients with coronary artery disease [21,22]. Therefore reduced IL- 6 release of T1D monocytes upon stimulation with HMW-APM may be beneficial in the development of atherosclerosis. However, impaired IL- 6 secretion may contribute to an ineffective innate immune response and higher incidence and duration of infections [23] and this may secondary promote atherogenesis.

In contrast to control monocytes, secretion of CCL2 is not altered by HMW-APM stimulation of T1D cells. Levels of CCL2 are increased early in the course of plaque formation and lead to increased monocyte migration into the atherosclerotic lesion [24]. Monocytes migrate into the intima due to a CCL2 concentration gradient that is formed by endothelial cells and monocytes [25]. Lower expression of CCL2 by T1D cells may increase this gradient and enhance migration of monocytes to the endothelium similar to a recent publication where an increase in CCL2 expression in adipose tissue enhances macrophage infiltration to this site [26]. Furthermore CCL2 is decreased in the plasma of T1D patients [27] and dimin- ished secretion of CCL2 by monocytes may contribute to reduced plasma levels. The chemokine CXCL8 also activates monocytes and may recruit these cells to the endothelium. CXCL8 was found to be reduced by adiponectin purified from human plasma in macrophages when the cells were cultivated in the presence of apoptotic cells and was induced in the absence of apoptotic cells or when endotoxin was added to the macrophages. These authors suggest that adiponectin is a dual modulator of innate responses and not an antiinflammatory adipokine [3].

The current data indicate that HMW-APM signal transduction pathways are impaired in T1D monocytes. Therefore elevated circulating adiponectin may be less protective in T1D patients when compared to healthy individuals.

\section{Conclusion}

Taken together, the present study demonstrates that T1D monocytes have a lower secretion of IL-6 and fail to induce CCL2 and CXCL8 when treated with HMW-APM. Therefore elevated systemic adiponectin in T1D patients may not reduce the risk to develop cardiovascular disease.

\section{Abbreviations}

Apolipoprotein E (Apo E), high-molecular weight adiponectin (HMW-APM), interleukin-6 (IL-6), interleukin8 (IL-8, CXCL8), macrophage colony stimulating factor (M-CSF), monocyte chemotactic protein-1 (CCL2, MCP1), type 1 diabetes (T1D).

\section{Declaration of competing interests}

The author(s) declare that they have no competing interests.

\section{Authors' contributions}

SA and MN collected monocytes from controls and carried out immunoassays and immunoblots, JW carried out immunoassays, GW collected the patients and control samples and carried out immunoassays, EE carried out immunoassays, AS participated in the design of the study; KM carried out immunoassays, CA was involved in discussions and preparation of the manuscript and, JS is the head of the department and provided the required resources for research and was involved in fruitful discussions and preparation of the manuscript, CB conceived of the study, and participated in its design and coordination and prepared the manuscript.

\section{Acknowledgements}

The technical assistance of Kerstin Winkler and Natalie Smolnikow is greatly appreciated. This work was partly supported by the Deutsche Diabetes-Stiftung. 


\section{References}

I. Okamoto Y, Kihara S, Funahashi T, Matsuzawa Y, Libby P: Adiponectin: a key adipocytokine in metabolic syndrome. Clin Sci (Lond) 2006, I I 0:267-278.

2. Neumeier M, Weigert J, Schaffler A, Wehrwein G, Muller-Ladner U, Scholmerich J, Wrede C, Buechler C: Different effects of adiponectin isoforms in human monocytic cells. J Leukoc Biol 2006, 79:803-808.

3. Saijo S, Nagata K, Nakano Y, Tobe T, Kobayashi Y: Inhibition by adiponectin of IL-8 production by human macrophages upon coculturing with late apoptotic cells. Biochem Biophys Res Commun 2005, 334: I 180-I I83.

4. Tsao TS, Murrey HE, Hug C, Lee DH, Lodish HF: Oligomerization state-dependent activation of NF-kappa B signaling pathway by adipocyte complement-related protein of $30 \mathrm{kDa}$ (Acrp30). J Biol Chem 2002, 277:29359-29362.

5. Bouma G, Coppens JM, Lam-Tse WK, Luini W, Sintnicolaas K, Levering WH, Sozzani S, Drexhage HA, Versnel MA: An increased MRP8// 4 expression and adhesion, but a decreased migration towards proinflammatory chemokines of type I diabetes monocytes. Clin Exp Immunol 2005, I 4I:509-5I7.

6. Du JH, Xu N, Song Y, Xu M, Lu ZZ, Han C, Zhang YY: AICAR stimulates IL-6 production via p38 MAPK in cardiac fibroblasts in adult mice: a possible role for AMPK. Biochem Biophys Res Commun 2005, 337: II39-I|44.

7. Rovin $\mathrm{BH}$, Song $\mathrm{H}$ : Chemokine induction by the adipocytederived cytokine adiponectin. Clin Immunol 2006, I 20:99-105.

8. Remick DG: Interleukin-8. Crit Care Med 2005, 33:S466-7.

9. DeForge LE, Fantone JC, Kenney JS, Remick DG: Oxygen radical scavengers selectively inhibit interleukin 8 production in human whole blood. J Clin Invest 1992, 90:21 23-2129.

10. Charo IF, Ransohoff RM: The many roles of chemokines and chemokine receptors in inflammation. N Engl J Med 2006, 354:610-62I.

I I. Frystyk J, Tarnow L, Hansen TK, Parving HH, Flyvbjerg A: Increased serum adiponectin levels in type I diabetic patients with microvascular complications. Diabetologia 2005, 48: I91 I-1918.

12. Heliovaara MK, Teppo AM, Karonen SL, Tuominen JA, Ebeling P: Improved glycaemia in type I diabetes results in decreased levels of soluble adhesion molecules with no change in serum adiponectin or most acute phase proteins. Exp Clin Endocrinol Diabetes 2006, I | 4:295-300.

13. Geerlings SE, Hoepelman Al: Immune dysfunction in patients with diabetes mellitus (DM). FEMS Immunol Med Microbiol I999, 26:259-265.

14. Wehrwein G, Neumeier M, Schaffler A, Kopp A, Weigert J, Abke S, Scholmerich J, Buechler C: Lipopolysaccharide regulated protein expression is only partly impaired in monocytes from patients with type I diabetes. Cardiovasc Diabetol 2006, 5:5.

15. Singer DE, Nathan DM, Anderson KM, Wilson PW, Evans JC: Association of HbAlc with prevalent cardiovascular disease in the original cohort of the Framingham Heart Study. Diabetes 1992, 4 I:202-208.

16. Patterson JE, Andriole VT: Bacterial urinary tract infections in diabetes. Infect Dis Clin North Am 1997, I I:735-750.

17. Lara-Castro C, Luo N, Wallace P, Klein RL, Garvey WT: Adiponectin multimeric complexes and the metabolic syndrome trait cluster. Diabetes 2006, 55:249-259.

18. Wulster-Radcliffe MC, Ajuwon KM, Wang J, Christian JA, Spurlock ME: Adiponectin differentially regulates cytokines in porcine macrophages. Biochem Biophys Res Commun 2004, 3 I 6:924-929.

19. Yokota T, Oritani K, Takahashi I, Ishikawa J, Matsuyama A, Ouchi N, Kihara S, Funahashi T, Tenner AJ, Tomiyama Y, Matsuzawa Y: Adiponectin, a new member of the family of soluble defense collagens, negatively regulates the growth of myelomonocytic progenitors and the functions of macrophages. Blood 2000, 96: $1723-1732$

20. Tsatsanis C, Zacharioudaki V, Androulidaki A, Dermitzaki E, Charalampopoulos I, Minas V, Gravanis A, Margioris AN: Adiponectin induces TNF-alpha and IL-6 in macrophages and promotes tolerance to itself and other pro-inflammatory stimuli. Biochem Biophys Res Commun 2005, 335: I 254-I 263.

21. Ridker PM, Rifai N, Stampfer MJ, Hennekens CH: Plasma concentration of interleukin-6 and the risk of future myocardial infarction among apparently healthy men. Circulation 2000, I01:1767-1772.
22. Koukkunen H, Penttila K, Kemppainen A, Halinen M, Penttila I, Rantanen T, Pyorala K: C-reactive protein, fibrinogen, interleukin6 and tumour necrosis factor-alpha in the prognostic classification of unstable angina pectoris. Ann Med 200I, 33:37-47.

23. Liberatore Rdel RJ, Barbosa SF, Alkimin MG, Bellinati-Pires R, Florido $M P$, Isaac L, Kirschfink M, Grumach AS: Is immunity in diabetic patients influencing the susceptibility to infections? Immunoglobulins, complement and phagocytic function in children and adolescents with type I diabetes mellitus. Pediatr Diabetes 2005, 6:206-2I2.

24. Charo IF, Taubman MB: Chemokines in the pathogenesis of vascular disease. Circ Res 2004, 95:858-866.

25. Rollins BJ, Yoshimura T, Leonard EJ, Pober JS: Cytokine-activated human endothelial cells synthesize and secrete a monocyte chemoattractant, MCP-I/JE. Am J Pathol 1990, I36:I229-I233.

26. Kanda H, Tateya S, Tamori Y, Kotani K, Hiasa K, Kitazawa R, Kitazawa S, Miyachi H, Maeda S, Egashira K, Kasuga M: MCP-I contributes to macrophage infiltration into adipose tissue, insulin resistance, and hepatic steatosis in obesity. J Clin Invest 2006, I | 6: | 494- I505.

27. Ferreira AM, Rollins BJ, Faunce DE, Burns AL, Zhu X, Dipietro LA: The effect of MCP-I depletion on chemokine and chemokine-related gene expression: evidence for a complex network in acute inflammation. Cytokine 2005, 30:64-7I.
Publish with Bio Med Central and every scientist can read your work free of charge

"BioMed Central will be the most significant development for disseminating the results of biomedical research in our lifetime. "

Sir Paul Nurse, Cancer Research UK

Your research papers will be:

- available free of charge to the entire biomedical community

- peer reviewed and published immediately upon acceptance

- cited in PubMed and archived on PubMed Central

- yours - you keep the copyright

Submit your manuscript here:

http://www.biomedcentral.com/info/publishing_adv.asp
BioMedcentral 